\title{
Ultrasound micromolding of porous polylactide/hydroxyapatite scaffolds
}

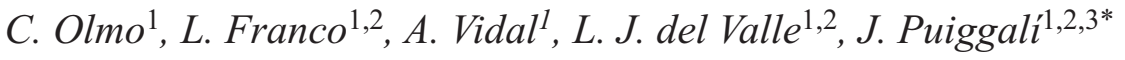 \\ ${ }^{1}$ Departament d'Enginyeria Química, Universitat Politècnica de Catalunya, Escola d'Enginyeria de Barcelona Est-EEBE, \\ 08019 Barcelona, Spain \\ ${ }^{2}$ Barcelona Research Center for Multiscale Science and Engineering, Universitat Politècnica de Catalunya, Escola \\ d'Enginyeria de Barcelona Est-EEBE, 08019 Barcelona, Spain \\ ${ }^{3}$ Institute for Bioengineering of Catalonia (IBEC), The Barcelona Institute of Science and Technology, Baldiri Reixac \\ 10-12, 08028 Barcelona, Spain
}

Received 6 July 2020; accepted in revised form 1 October 2020

\begin{abstract}
Ultrasound micromolding (USM) preparation of hybrid scaffolds based on polylactide (PLA) and hydroxyapatite (HAp) particles has been evaluated. PLA was stable under the applied ultrasound source since a minimum degradation was detected. Porous materials were achieved using polyethylene glycol (PEG) and $\mathrm{NaCl}$ salts to the initial PLA and the subsequent leaching of the micromolded specimens. To avoid cavitation and decomposition problems during micromolding, it was necessary to use HAp free of typical synthesis impurities like carbonate and nitrate compounds. Compact PLA/HAp pieces allowed a maximum HAp load of $60 \mathrm{wt} \%$, while porous specimens could be obtained with a maximum load of $38 \mathrm{wt} \%$. Physical characterization of new scaffolds was performed by X-ray diffraction, spectroscopic and calorimetric techniques, stress-strain tests and contact angle measurements. Results indicated that a degree of porosity of 35\% and relatively good mechanical properties could be achieved (i.e., $580 \mathrm{MPa}, 4 \%$, and $15.6 \mathrm{MPa}$ for the Young modulus, elongation at break, and tensile strength, respectively). Scaffolds showed the positive effect of HAp and porosity on cell proliferation; this latter was $40 \%$ higher than that detected for non-porous PLA specimens.
\end{abstract}

Keywords: processing technologies, ultrasound micromolding, micropieces, hydroxyapatite, porous scaffolds

\section{Introduction}

Hybrid materials based on biodegradable polymers are continuously being developed to cover a wide range of biomedical applications. Healing of skin and wounds, reconstruction of bone, cartilages, and muscles, reparation of the nervous system, regeneration of vasculature, and even drug delivery and gene therapy are examples. Probably, the development of new materials for tissue regeneration is one of the most promising areas since concentrates great research efforts. In tissue engineering, it is important to highlight the use of scaffolds to develop biological substitutes that restore or maintain the tissue function.
A biocompatible, biodegradable and cell colonizable material is required for the regeneration of the damaged tissue $[1,2]$. Therefore, efforts are focused on developing biocompatible synthetic polymeric systems to build porous matrices that can act as templates for new tissue formation. Matrices can also be seeded with either cells or specific grown factors to enhance proliferation, and/or loaded with fibers and particles such as HAp to increase biocompatibility [3].

HAp is usually selected as a component of biomaterials for being the main inorganic constituent of bones, for enhancing cell proliferation and for having a high bioactivity. HAp is obviously found in nature, but it 
can alternatively be synthesized by precipitation or hydrolysis following well-standardized procedures [4-6]. The use of HAp alone as a ceramic implant is limited because it is extremely brittle with low mechanical strength and fatigue failure [7, 8]. Thus, HAp is usually employed in a wide variety of biomedical applications in the form of composites. PLA is an ideal polymer matrix due to its biocompatibility, relatively low degradation rate, and good mechanical properties. Furthermore, PLA biodegrades into nontoxic products and has been approved by the food and drug administration (FDA) [9-12].

PLA/HAp scaffolds have been widely used in bone repair applications, showing very good osteoconductive and osteoinductive behaviors [13, 14]. These scaffolds have been prepared by several processes such as induced phase separation $[15,16]$, in situ polymerization $[17,18]$, mechanical dispersion, melt blending [19], in situ precipitation, and ultrasound methods [20, 21].

USM is a relatively new processing technique that uses ultrasound as a heating source. Specifically, energy is transferred to the polymer through increased vibration of the molecular chains. This heating process is really accurate and efficient, just melting the amount of material needed. Moreover, ultrasound vibration reduces the polymer viscosity facilitating the material pumping and mold filling [22]. The combination of the accurate energy transfer and dosing systems has made USM suitable for large production of microsized specimens with high spatial resolution [23-27]. USM seems ideal for producing pieces for biomedical applications where the added value materials are expensive, and an inefficient cost cycle would bring great economic losses as it may be the case of other alternative processes such as microinjection molding [28].

The efficiency of USM has already been proved for the production of microspecimens based on commodities like polyethylene, polypropylene and polystyrene $[29,30]$ and biodegradable polymers such as polylactide, polycaprolactone and polybutylene succinate $[24,31]$. All these previous studies have concluded that high-quality specimens can be produced after an accurate setting up of the wave amplitude, time, and pumping force molding parameters. USM has also been probed appropriately to produce nanocomposites (e.g., polylactide or poly( $\varepsilon$-caprolactone) incorporating nanoclays [32] or carbon nanotubes
[33], respectively), and even specimens with an added pharmacological activity [34].

The present work is focused on the preparation of PLA/HAp composites by USM, taking into consideration the influence of the origin of the inorganic component and evaluating particle distribution and processing parameters. USM preparation of porous PLA/HAp composites is a second goal of the present work that appears fundamental for applications like tissue engineering where cell colonization is required.

\section{Experimental}

\subsection{Materials}

Ecorene ${ }^{\circledR}$ NW30 (NatureWorks, Naarden, The Netherlands), a commercial-grade of PLA powder with a number average molecular weight of $43000 \mathrm{~g} / \mathrm{mol}$ and a high crystallization degree (i.e., 35\%) was employed. CHT ceramic hydroxyapatite type I was provided by Bio-Rad (Hercules, Cal, USA). This HAp was constituted by rather homogeneous particles with sizes smaller than $200 \mu \mathrm{m}$. Polyethylene glycol (PEG) $\left(M_{\mathrm{w}}: 100000 \mathrm{~g} / \mathrm{mol}\right)$, sodium chloride $(\mathrm{NaCl})$, and $\mathrm{NH}_{4} \mathrm{OH}$ were provided by Sigma-Aldrich (Sant Louis, MO, USA). $\mathrm{NaCl}$ was sieved in order to get particles with sizes smaller than $100 \mu \mathrm{m}$.

\subsection{USM equipment and molding process}

The main parts of the USM equipment (Sonorus ${ }^{\circledR}$, Ultrasion S.L., Barcelona, Spain) are schematized in Figure 1. The USM process requires a digital ultrasound generator $(1000 \mathrm{~W}-30 \mathrm{kHz})$, a controller (3010 DG digital system, Mecasonic, Barcelona, Spain), a focused piezoelectric transducer (Mecasonic, Barcelona, Spain), which converts electrical energy into kinetic energy and creates undulatory movement, and an acoustic unit constituted by a booster and a sonotrode that operates in longitudinal vibration. The first element amplifies or reduces the wave amplitude $(0-137.5 \mu \mathrm{m})$ while the second transfers vibration energy to the material and provides the pressure/force required to transfer it into the mold. The equipment is also provided with an electric servomotor control (Berneker and Rainer, Barcelona, Spain) fitted with software from Ultrasion S.L. (Barcelona, Spain), a little plasticizing camera, and a mold capable of preparing 8 test specimens of dimensions $1.5 \mathrm{~cm} \times 0.1 \mathrm{~cm} \times 0.1 \mathrm{~cm}$, and an automatic ejection system. 


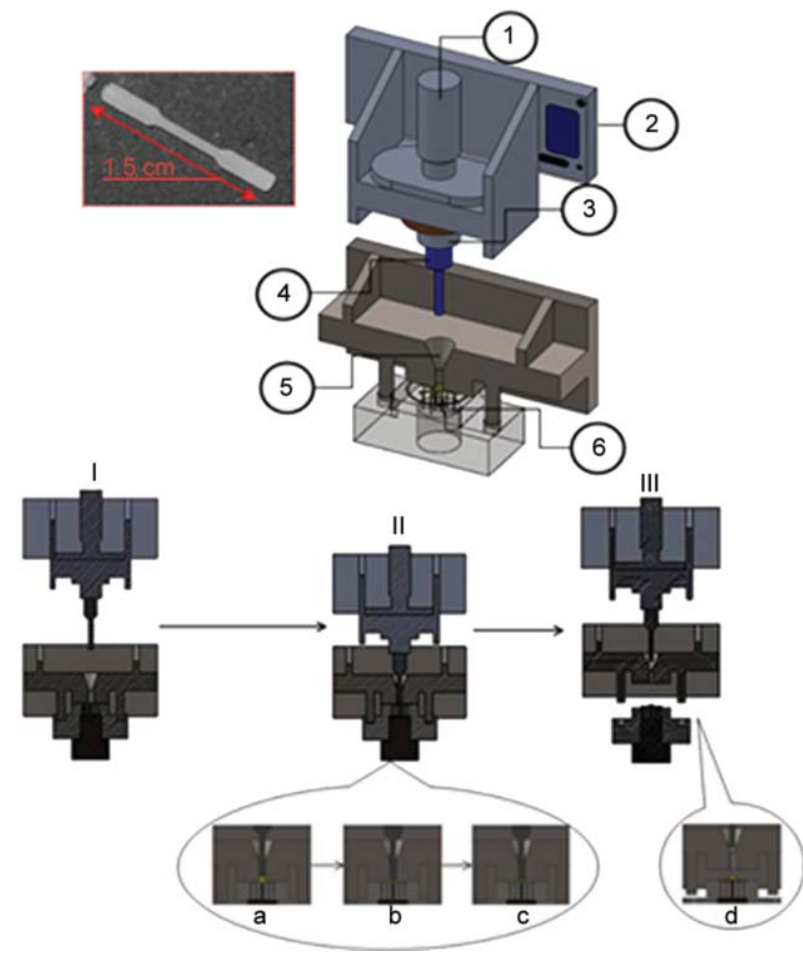

Figure 1. Scheme showing the main parts of the USM equipment (1: Transducer, 2: Controller and generator, 3: Booster, 4: Sonotrode, 5: Plasticizing camera and 6: Mold and ejectors). An example of a processed specimen is given in the upper left of the Figure and a representation of the molding process (I: Feeding, II: Molding and III: Ejection stages) is illustrated in the lower part.

Each micromolding experiment was performed with around $380 \mathrm{mg}$ of powdered material that was loaded directly to the feeding/plasticizing camera of the USM equipment. When mixtures were employed (e.g., those involving PLA, NaCl, PEG and/or HAp), the appropriate amount of each powdered component was externally mixed. Samples were processed with the optimized molding parameters (amplitude, force, and time) that were kept as close as possible to those already determined for neat PLA in previous works [46]. In the case of porous specimens (scaffolds), a subsequent wash for $24 \mathrm{~h}$ was needed to remove the added water-soluble $\mathrm{NaCl}$ and PEG components.

The complete molding process can be described by three steps. In the first one the mold is closed and the sonotrode in the feeding position (stage I in Figure 1). Then, the powdered sample (i.e., PLA or the different mixtures with the added compounds) is loaded into the plasticizing camera. The second step is the main one and consists of three substages: a) the sonotrode firstly compacts the powdered mixture applying the selected force and acting as a piston (stage II-a in Figure 1), b) the sonotrode begins to vibrate according to the selected amplitude that is regulated by the booster. The polymer begins to flow and fill the mold cavities (stage II-b), c) after the selected time set up, the sonotrode vibration stops, and the mold is cooled down, while the sample is still compacted by the sonotrode (stage II-c). Finally, the mold is opened, the sonotrode returns to the feeding position, and the sample is released from the mold by the ejection system (stage III).

Processed samples will be named, indicating the amount of each component if it is different from zero. Thus, PLA-40/PEG-10/NaCl-25/HAp-25 means an initial mixture having $40,10,25$, and $25 \mathrm{wt} \%$ of PLA, PEG, $\mathrm{NaCl}$, and $\mathrm{HAp}$, respectively.

\subsection{Synthesis of hydroxyapatite}

HAp was synthesized by precipitation at room temperature following the procedure described by Zhang and $\mathrm{Lu}$ [5]. $500 \mathrm{mM}$ of $\mathrm{Ca}\left(\mathrm{NO}_{3}\right)_{2} \cdot \mathrm{H}_{2} \mathrm{O}$ in ethanol and $500 \mathrm{mM}$ of $\mathrm{NH}_{4} \mathrm{PO}_{4}$ in water $(\mathrm{pH}<10)$ were vigorously stirred at room temperature for $1 \mathrm{~h}$. Reagent volumes were determined to get a $\mathrm{Ca} / \mathrm{P}$ ratio of 1.67 , which is the typical value for natural HAp [35]. The $\mathrm{pH}$ of the medium was adjusted by adding $\mathrm{NH}_{4} \mathrm{OH}$. The mixture was kept at $37^{\circ} \mathrm{C}$ for $24 \mathrm{~h}$, and after that, the product was washed with milli-Q water and centrifuged four times at $5000 \mathrm{rpm}$. The precipitated extract was frozen overnight at $-80^{\circ} \mathrm{C}$, and then it was dried at low temperature for $48 \mathrm{~h}$. The HAp obtained was ground and filtered.

\subsection{Leaching of $\mathrm{NaCl}$ : mass extraction yield and porosity calculations}

$\mathrm{NaCl}$ extraction was calculated by measuring the conductivity of the washing water with an SX-650 Sanxin electrical conductivity meter $(0-50 \mathrm{mS} / \mathrm{cm})$. Calibration was performed with standard $\mathrm{NaCl}$ solutions at $21^{\circ} \mathrm{C}$. Values were averaged from three measurements. The weight of the removed salt, $W_{\mathrm{r}}$, was calculated according to Equation (1):

$W_{\mathrm{r}}=\frac{V \cdot(\sigma-b)}{a}$

where $V$ is the volume of washing water [ml], $\sigma$ is the conductivity $[\mathrm{S} / \mathrm{m}]$, and $a$ and $b$ calibration constants.

The yield of extracted salt, $r_{\mathrm{NaCl}}$, was then determined as Equation (2): 
$r_{\mathrm{NaCl}}[\%]=100 \cdot \frac{W_{1}-W_{\mathrm{r}}}{W_{1}}$

where $W_{1}$ is the theoretical weight of salt loaded in the specimen.

The weight percentage of extracted sample (i.e., salt plus PEG), $W_{\mathrm{e}}$, was calculated from the theoretical weight of $\mathrm{NaCl}$ and PEG in the specimen, $W_{1} t$, and the weights of the specimen before being washed, $W_{0}$, and once the washed specimen was dried, $W_{\mathrm{d}}$ (Equation (3)):

$W_{\mathrm{e}}[\%]=100 \cdot \frac{W_{0}-W_{\mathrm{d}}}{W_{1} t}$

The porosity of each specimen, $P$, was finally estimated, according to Equation (4):

$$
P[\%]=100 \frac{\frac{W_{0}-W_{\mathrm{w}}}{\delta_{\mathrm{w}}}}{\sum \frac{W_{\mathrm{i}}}{\delta_{\mathrm{i}}}}
$$

where $W_{\mathrm{w}}$ is the weight of the wet specimen after being washed, $W_{\mathrm{i}}$ is the loaded weight of each component (i.e., PLA, PEG, and HAp), $\delta_{\mathrm{w}}$ is the water density, and $\delta_{\mathrm{i}}$ the density of each component.

\subsection{Specimen characterization}

Molecular weight was determined by gel permeation chromatography (GPC) using a liquid chromatograph (Shimadzu, model LC-8A, Tokyo, Japan) equipped with an Empower computer program (Waters, Milford, MA, USA). The polymer was dissolved and eluted in 1,1,1,3,3,3-hexafluoroisopropanol (HFIP) containing $\mathrm{CF}_{3} \mathrm{COONa}(0.05 \mathrm{M})$. The flow rate was $1 \mathrm{~mol} / \mathrm{min}$, the injected volume $20 \mu \mathrm{l}$, and the sample concentration $2 \mathrm{mg} / \mathrm{ml}$. A PL HFIP gel column (Polymer Lab, Agilent Technologies Deutschland $\mathrm{GmbH}$, Böblingen, Germany) and a refractive index detector (Shimadzu RID-10A, model LC-8A, Tokyo, Japan) were employed. The number and weight average molecular weights were determined using polymethyl methacrylate standards.

Infrared spectra (ATR-FTIR) were recorded at a resolution of $4 \mathrm{~cm}^{-1}$, with a Fourier transform FTIR 4100 Jasco spectrometer (Tokyo, Japan) dotted with a Specac MKII Golden Gate Single Reflection Diamond ATR system (Jasco International, Tokyo, Japan).

Scanning electron microscopy (SEM) images of micromolded specimens were taken by using a Focused Ion Beam Zeiss Neon40 microscope (Zeiss,
Oberkochen, Germany) operating at $5 \mathrm{kV}$. Samples were mounted on a double-side adhesive carbon disc and sputter-coated with a thin layer of carbon by using a Mitec K950 Sputter Coater (Quorum Technologies Ltd., Ashford, UK).

Contact angles (CA) were measured at room temperature with sessile drops using an OCA-15 plus Contact Angle Microscope (Dataphysics, USA) and SCA20 software. Contact angle values of the right and left sides of distilled water drops were measured and averaged. Measurements were performed $10 \mathrm{~s}$ after the drop $(0.5 \mu 1)$ was deposited on the sample surface. All CA data were an average of six measurements on different surface locations.

Calorimetric data were obtained by differential scanning calorimetry with a TA Instruments Q100 series (TA instruments, New Castle, DE, USA) with Tzero technology and equipped with a refrigerated cooling system (RCS, TA instruments, New Castle, DE, USA). Experiments were conducted at a heating rate of $10^{\circ} \mathrm{C} / \mathrm{min}$ and under a flow of dry nitrogen. The sample weight was approximately $5 \mathrm{mg}$, and calibration was performed with indium.

Thermogravimetric analysis (TGA) and differential thermogravimetric analysis (DTGA) were performed with a Q50 thermogravimetric analyzer of TA Instruments (New Castle, DE, USA) under a flow of dry nitrogen with approximately $5 \mathrm{mg}$ samples and at a heating rate of $10^{\circ} \mathrm{C} / \mathrm{min}$.

Real-time synchrotron studies at variable temperatures were carried out on beamline BL11-NCD at ALBA Synchrotron (Cerdanyola del Vallès, Barcelona, Spain) by using a wavelength of $0.100 \mathrm{~nm}$ and a WAXD LX255-HS detector from Rayonix. Polymer samples were confined between Kapton films and then held on a Linkam hot stage (Tadworth, UK) with temperature control within $\pm 0.1^{\circ} \mathrm{C}$. WAXD profiles were acquired during the heating runs in time frames of $20 \mathrm{~s}$ and a rate of $10^{\circ} \mathrm{C} / \mathrm{min}$. WAXD diffraction patterns were calibrated by means of a geometrical calibration process of a well-known sample (standard $\mathrm{Cr}_{2} \mathrm{O}_{3}$ ). Diffraction profiles were normalized to the beam intensity and corrected, considering the empty sample background.

\subsection{Cell proliferation studies}

MDCK cells (Madin-Darby Canine Kidney epithelial-like cell line) (American Tissue Cell Culture, ATCC, USA) were cultured in Dulbecco's modified Eagle's medium (i.e., DMEM with $4500 \mathrm{mg} / 1$ of 
glucose, $110 \mathrm{mg} / 1$ of sodium pyruvate, and $2 \mathrm{mM}$ of L-glutamine) supplemented with $10 \%$ fetal bovine serum (FBS), $50 \mathrm{U} / \mathrm{ml}$ penicillin, $50 \mathrm{mg} / \mathrm{ml}$ streptomycin and $2 \mathrm{mM} \mathrm{L}$-glutamine at $37^{\circ} \mathrm{C}$ in a $10 \%$ humidified atmosphere of $5 \% \mathrm{CO}_{2}$ and $95 \%$ air. $\mathrm{Cul}-$ ture media were changed every two days. For subculture, cell monolayers were rinsed with PBS and detached by incubating them with $0.25 \%$ trypsin/ EDTA for $25 \mathrm{~min}$ at $37^{\circ} \mathrm{C}$. The incubation was stopped by resuspending in $5 \mathrm{ml}$ of fresh medium. Cell concentration was determined by counting with a Neubauer camera (Sigma-Aldrich, Sant Louis, MO, USA) and using 4\% trypan blue as dye vital.

PLA/HAp scaffold, PLA scaffold, and PLA nonporous sample were placed in polyester plates, sterilized, exposed to UV light for $15 \mathrm{~min}$, and finally treated for cell culture. $100 \mu 1$ containing $5 \cdot 10^{4}$ cells were deposited in the plate and incubated for $60 \mathrm{~min}-$ utes. Then, $1 \mathrm{ml}$ of culture media was added to each plate. Quantification of proliferated cells was performed after one week.

Percentages of proliferated cells were calculated through the 3-(4,5-dimethylthiazol-2-yl)-2,5-diphenyltetrazolium bromide (MTT) assay [36]. This determines the ability of the mitochondrial dehydrogenase enzyme of viable cells to cleave the tetrazolium rings of MTT and form formazan crystals that are accumulated in healthy cells. This process is detected and can be quantified through a color change: the characteristic pale yellow of MTT transforms into the dark blue of formazan crystals. Specifically, $50 \mu \mathrm{l}$ of MTT ( $3 \mathrm{mg} / \mathrm{ml})$ was added after a week to the culture plates, which were further incubated for $4 \mathrm{~h}$. Samples were subsequently washed twice with Phosphate-Buffered Saline (PBS; 0.1 M, pH 7.4: $80 \mathrm{~g}$ $\mathrm{NaCl}, 2.0 \mathrm{~g} \mathrm{KCl}, 21.7 \mathrm{~g} \mathrm{Na}_{2} \mathrm{HPO}_{4} \cdot 7 \mathrm{H}_{2} \mathrm{O}, 2.59 \mathrm{~g}$ $\mathrm{KH}_{2} \mathrm{PO}_{4}$ ) and deposited in a new plate. Then, $1 \mathrm{ml}$ of dimethyl sulfoxide (DMSO) was added, and the absorbance was measured at $540 \mathrm{~nm}$ in Elisa EZRead 400 (Biochrom, Cambridge, UK) after $15 \mathrm{~min}$ of gently stirring. Values were averaged according to three measured replicas. Controls were conducted by cell culture on the wells without any material. The statistical analysis was performed by one-way ANOVA, followed by Tukey test with a confidence level of 95\% $(p<0.05)$.

To obtain representative fluorescence images of samples coming from the proliferation assay, samples were fixed in glutaraldehyde ( $2.5 \%$ in PBS) overnight at $4{ }^{\circ} \mathrm{C}$, and then dehydrated by extensive washing in an alcohol battery. Finally, samples were dried in air and sequentially stained with green-fluorescent Alexa Fluor Atto-488 phalloidin dye and 4',6-diamidino-2phenylindole (DAPI) for labeling actin and nucleus, respectively. The images were obtained with a confocal laser scanning microscope (LSM 900 Zeiss) controlled by ZEN 2.6 software (blue edition) (CarlZeiss Microscopy GmbH, Jena, Germany).

\section{Results and discussion \\ 3.1. Ultrasound micromolding of PLA/HAp composites}

The ability to prepare uniform PLA/HAp composites by means of the USM technique has been explored considering the HAp type (i.e., commercial or synthesized), the particle size, and the maximum allowed load.

The starting USM processing parameters were those previously determined for the commercial PLA powder sample: amplitude, force, and time of $24 \mu \mathrm{m}$, $300 \mathrm{~N}$, and $1.2 \mathrm{~s}$. Basically, previous studies indicated that lower amplitudes were not enough to get an appropriate PLA flow and that $300 \mathrm{~N}$ was the minimum force that allowed to fill the mold cavities completely. Forces higher than $500 \mathrm{~N}$ caused an overloading of the sonotrode (i.e., it could not vibrate as a consequence of the high compaction of PLA). Processing time of only $1.2 \mathrm{~s}$ was enough and therefore was selected for all experiments since a slight degradation was noticed for times higher than $3 \mathrm{~s}$. Table 1 summarizes representative GPC data for the assays performed with PLA. Note that a minimum variation of $M_{\mathrm{n}}$ from 43000 to $38800 \mathrm{~g} / \mathrm{mol}$ (i.e., less than $10 \%$ ) was determined when PLA was processed under the indicated optimal conditions.

Table 1. Influence of USM processing parameters on the molecular weight of polylactide specimens.

\begin{tabular}{|l|c|c|c|}
\hline Molding parameters $^{\mathbf{a}}$ & Mold filling $^{\mathbf{b}}$ & $\begin{array}{c}\boldsymbol{M}_{\mathbf{n}} \\
{[\mathbf{g} / \mathbf{m o l}]}\end{array}$ & $\begin{array}{c}\boldsymbol{M}_{\mathbf{w}} \\
{[\mathbf{g} / \mathbf{m o l}]}\end{array}$ \\
\hline Commercial sample & - & 43000 & 69100 \\
\hline $24-200-1.5$ & $40 \%$ & 35400 & 69700 \\
\hline $24-300-1.2$ & $100 \%$ & 38800 & 72200 \\
\hline $24-300-3.0$ & $100 \%$ & 32200 & 64300 \\
\hline $24-400-1.2$ & $100 \%$ & 37700 & 71300 \\
\hline $24-500-1.2$ & - Ovl- & 33900 & 67500 \\
\hline $24-600-1.2$ & - Ovl- & - & - \\
\hline
\end{tabular}

${ }^{a}$ Amplitude [ $\left.\mu \mathrm{m}\right]$-Force $[\mathrm{N}]-$ Time [s].

${ }^{\mathrm{b}}$ Qualitative evaluation (e.g., 8 half specimens or 4 complete specimens correspond to $50 \%$ ). Sonotrode overload is indicated as -Ovl-. 


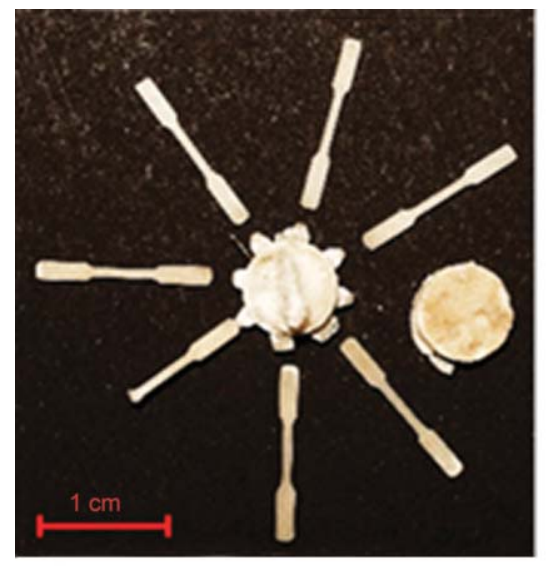

a)

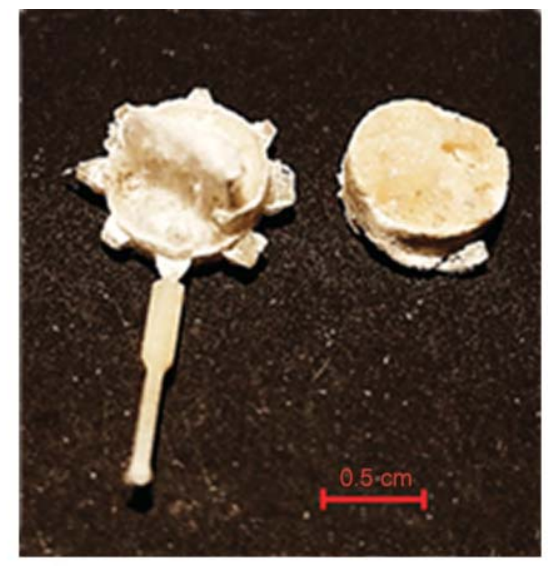

b)

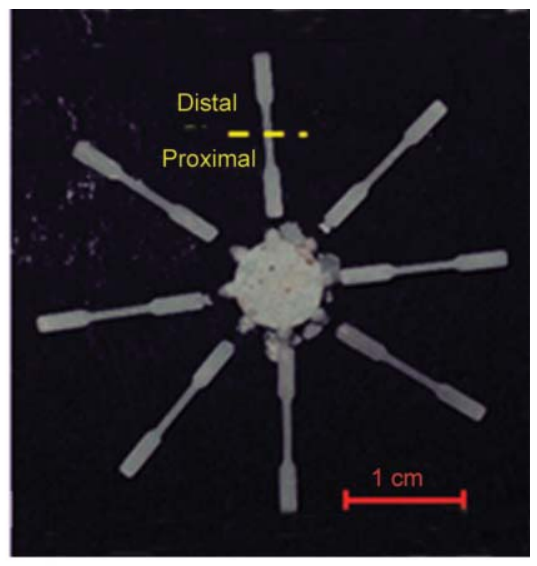

c)

Figure 2. Molded specimens, with synthesized (a, b) and commercial-grade HAp (c). HAp contents were 20 and $60 \mathrm{wt} \%$ for synthesized and commercial particles, respectively. Images of processed specimens incorporating synthesized HAp were obtained with sieved granules in the 100-80 $\mu \mathrm{m}$ size range. Proximal and distal parts of a given specimen are indicated in (c).

PLA composites were not able to be well-molded when the synthesized HAp was employed. For a load of $50 \mathrm{wt} \%$ the equipment only compacted the powdered mixture, which therefore could not properly flow and fill the mold. Results progressively improved when the load decreased down to $30 \mathrm{wt} \%$. The fluidization of the material was achieved when the HAp amount was decreased to $20 \mathrm{wt} \%$, but the whole mold could still not be completely filled, and some of the final specimens resulted in being uncompleted despite the fact that the force was increased up to $400 \mathrm{~N}$ (Figure 2).

Synthesized HAp corresponds to nanometric crystals that, unfortunately, become agglomerated (Figure 3), giving rise to granules with a broad size distribution. These granules could be sieved into fractions with sizes of $250-125,100-80,80-45$, and $<45 \mu \mathrm{m}$, it is, therefore, possible to evaluate the effect of the particle size on the micromolding effectivity. Note that the high dimensions of aggregates may difficult the correct flow of the mixture towards the mold when the content of the inorganic component is high.

The indicated fractions of synthetic HAp were subsequently used in USM experiments that were carried out with a HAp load of $20 \mathrm{wt} \%$ and processing parameters of $24 \mu \mathrm{m}, 400 \mathrm{~N}$, and $1.2 \mathrm{~s}$. The main observed effect was a lower capacity of HAp to load the mold when the particle size increased. Namely, HAp preferably remained in the sprue for increasing sizes. This heterogeneous distribution could be easily evaluated through density measurements of representative parts (i.e., sprue and specimen). Thus, densities determined by the flotation method using

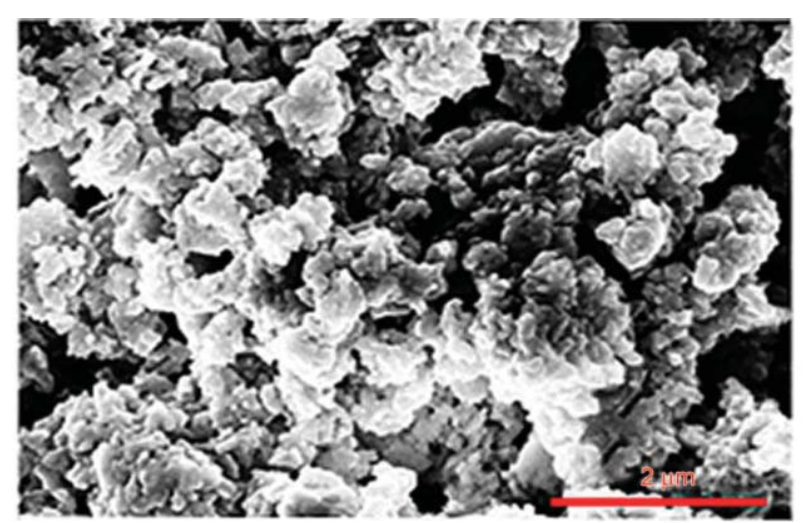

a)

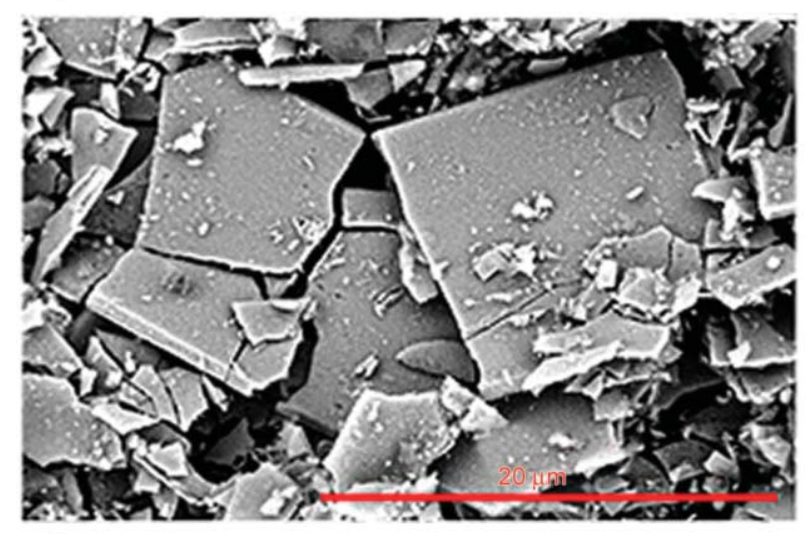

b)

Figure 3. SEM micrographs, showing typical morphologies of synthesized (a) and commercial (b) HAp crystals.

water and a $\mathrm{KBr}$ saturated aqueous solution were $1.81 \mathrm{~g} / \mathrm{ml}$ (sprue) and $1.41 \mathrm{~g} / \mathrm{ml}$ (specimen) when the $250-125 \mu \mathrm{m}$ fraction was employed, $1.72 \mathrm{~g} / \mathrm{ml}$ (sprue) and $1.52 \mathrm{~g} / \mathrm{ml}$ (specimen) for the 100-80 $\mu \mathrm{m}$ fraction, $1.69 \mathrm{~g} / \mathrm{ml}$ (sprue) and $1.55 \mathrm{~g} / \mathrm{ml}$ (specimen) for the $80-45 \mu \mathrm{m}$ fraction, and 1.66 and $1.58 \mathrm{~g} / \mathrm{ml}$ 
for the $<45 \mu \mathrm{m}$ fraction. Note that a value close to $1.62 \mathrm{~g} / \mathrm{ml}$ should be expected for a sample with a HAp load of $20 \mathrm{wt} \%$ considering theoretical densities of 1.24 and $3.16 \mathrm{~g} / \mathrm{ml}$ for PLA and HAp, respectively.

The inspection of processed samples (Figure 2) indicated that the sprue was plenty of bubbles; the material had a slight brown coloration and was very brittle. Observations pointed out the possibility of gas formation, cavitation phenomena, and degradation. Therefore, the use of synthetic particles was discarded for the rest of the experiments.

USM of mixtures with commercial HAp was completely different since good results were attained even for a high load of $60 \mathrm{wt} \%$. In all cases, the applied force should be $400 \mathrm{~N}$ in order to get a perfect specimen (using amplitude and time of $24 \mu \mathrm{m}$, and $1.2 \mathrm{~s}$, respectively). Lower forces were inefficient to fill the mold completely even when the HAp content was reduced to $10 \mathrm{wt} \%$. Figure 2 shows that eight perfect specimens were obtained for the maximum load. Furthermore, no coloration and degradation evidence could be observed. In addition, cavitation phenomena were not detected since bubbles were absent.

The morphology of commercial HAp particles was completely different from that observed for the synthesized sample, as shown in Figure 3. In this case, HAp crystals had a regular sheet-like morphology with its larger dimension close to $10 \mu \mathrm{m}$. The brittle character of HAp caused some breakage of crystals during preparation, as detected in Figure 3. Nevertheless, the commercial HAp sample was rather homogeneous in size according to the weight of the different sieved fractions, and consequently, the effect of the particle dimensions on the distribution inside the molded specimen was not evaluated. Density measurements pointed out again a slight difference between sprue and specimen, which become more significant as the HAp load increased. Thus, densities of $2.46 \mathrm{~g} / \mathrm{ml}$ (sprue) and $2.27 \mathrm{~g} / \mathrm{ml}$ (specimen) and $1.64 \mathrm{~g} / \mathrm{ml}$ (sprue) and $1.60 \mathrm{~g} / \mathrm{ml}$ (specimen) were found for loads of 60 and $20 \mathrm{wt} \%$, respectively. Samples with an intermediate load of $40 \mathrm{wt} \%$ could already be considered practically homogeneous with densities of $2.23 \mathrm{~g} / \mathrm{ml}$ (sprue) and $2.12 \mathrm{~g} / \mathrm{ml}$ (specimen). Homogeneity inside the specimen was also evaluated by analyzing two half parts of each specimen: proximal (P) and distal (D) parts along the flow direction (Figure 2c). In this case, minimum differences were found, and for example, density values of $2.10 \mathrm{~g} / \mathrm{ml}$ (distal) and $2.14 \mathrm{~g} / \mathrm{ml}$ (proximal) were determined for the sample having $40 \mathrm{wt} \%$ of HAp. Finally, it can be pointed out that similar particle distribution was found for samples having a $20 \mathrm{wt} \%$ load of synthetic (i.e., densities of $1.66 \mathrm{~g} / \mathrm{ml}$ (sprue) and $1.58 \mathrm{~g} / \mathrm{ml}$ (specimen) for the $<45 \mu \mathrm{m}$ fraction) and commercial (i.e., densities of $1.64 \mathrm{~g} / \mathrm{ml}$ (sprue) and $1.60 \mathrm{~g} / \mathrm{ml}$ (specimen)) particles. Therefore, USM seems a suitable process to get a homogeneous particle dispersion even for high loads and particle sizes in the micrometer range.

SEM micrographs of processed specimens (Figure 4) clearly revealed the presence of HAp particles inside the PLA continuous matrix with a rather homogeneous distribution in the inner cross-sections and an irregular distribution on the specimen surface.

FTIR analysis allowed explaining the negative effect of synthesized HAp in comparison with the commercial-grade sample. Clear differences can be observed between both spectra, as shown in Figure 5.

Thus, the commercial-grade sample had a high purity, and only typical bands for the phosphate compound at 1090,1020, $960 \mathrm{~cm}^{-1}$ were detected [35, $37,38]$. By contrast, some other minor bands (see blue ellipsoids) were observed in the synthesized sample. Note the bands around $1740-1600 \mathrm{~cm}^{-1}$ that can be associated with carbonyl groups of carbonated HAp [39]. Furthermore, the band at $1360 \mathrm{~cm}^{-1}$ can be related to residual nitrates. The $\mathrm{CO}_{2}$ formation caused by the degradation of carbonate by ultrasound heating leads to internal cracks, enclosed bubbles, and poor heat conductivity. The presence of nitrates also negatively affected the characteristics of the molded specimen since when heated, burned and colored the sample.

In summary, the use of synthesized HAp requires exhaustive cleaning and purification steps in order to avoid the presence of carbonated or nitrates byproducts. Despite the fact that HAp nanocrystals are highly interesting for biomedical applications, the rest of the study is performed with the commercial sample to avoid the effect of impurities. Finally, a careful drying is essential to reduce the moisture absorbed when hygroscopic salts are added, as will be mentioned later in the section concerning the preparation of porous scaffolds. Moisture can render bubbles and lead to a cavitation phenomenon as also observed for some samples (not shown). 


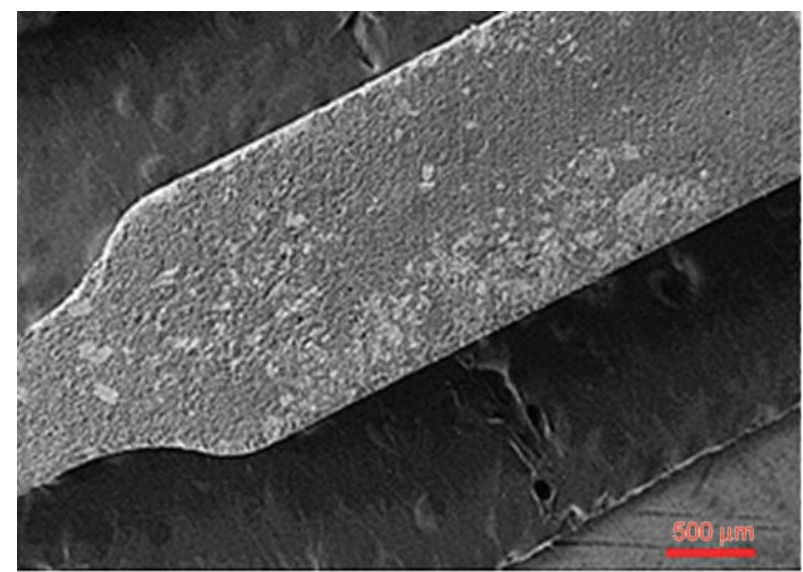

a)

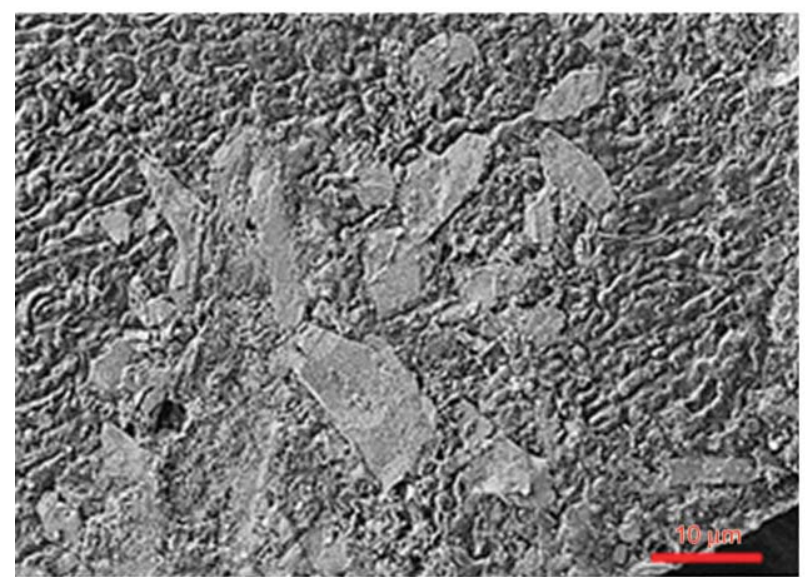

c)

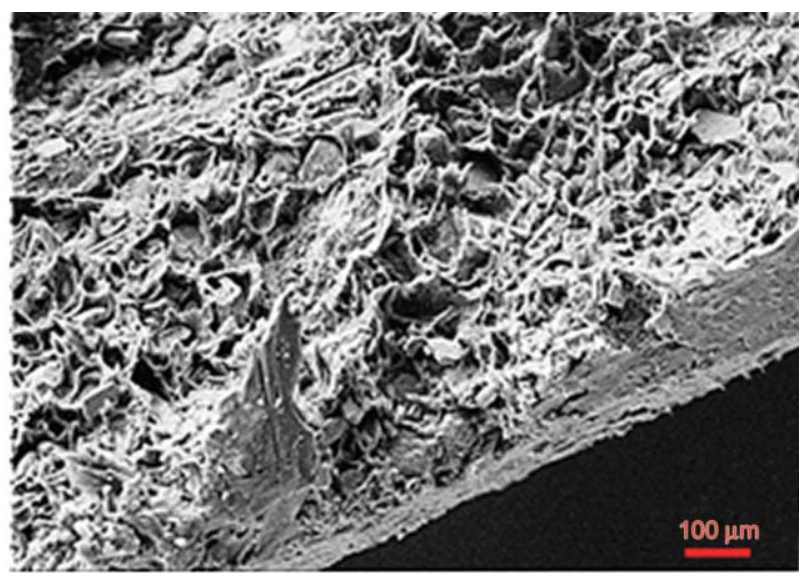

b)

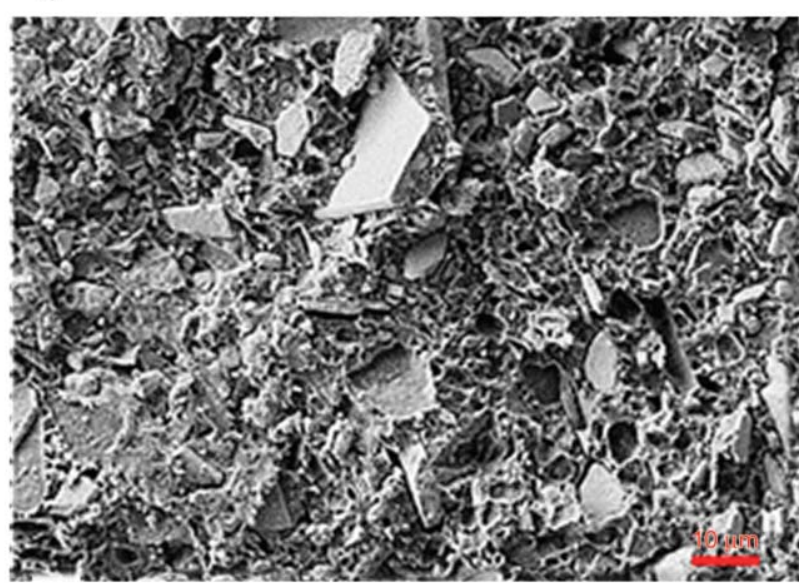

Figure 4. SEM micrographs showing the surface (a, c) and inner cross-sections (b, d) of a PLA micromolded specimen having $40 \mathrm{wt} \%$ of commercial HAp. Low magnification images allowed to determine the type of distribution (homogeneous or irregular), while the platelet-like morphology of the incorporated HAp particles could be clearly observed in the high magnification images.

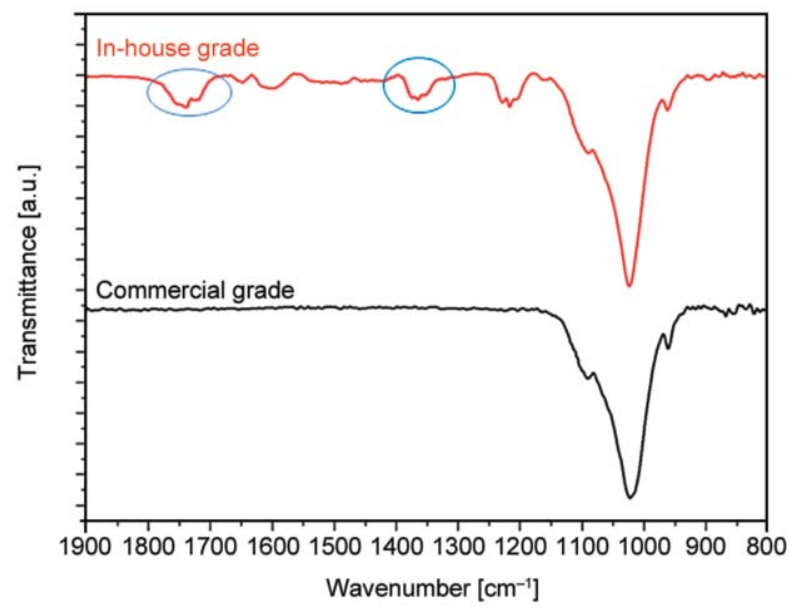

Figure 5. FTIR spectrum of synthesized HAp (red line) and commercial HAp (black line).

\subsection{Characterization of PLA/HAp micromolded specimens}

Micromolded composite specimens were characterized considering the GPC molecular weight, thermal properties, crystalline structure, and mechanical properties.

Figure 6 compares the GPC curves of the commercial PLA powder, the processed PLA specimen, and the PLA-HAp composite specimen having the maximum load (i.e., $60 \mathrm{wt} \%$ ). Specimens were processed using the above indicated optimal parameters (i.e., $24 \mu \mathrm{m}, 300 \mathrm{~N}$, and $1.2 \mathrm{~s}$ for PLA and $24 \mu \mathrm{m}, 400 \mathrm{~N}$, and $1.2 \mathrm{~s}$ for the composite). Processing of PLA leads to a small increase of the tail of the curve corresponding to the smallest molecular weight fraction, and therefore, minor evidence of degradation could be detected through the $M_{\mathrm{n}}$ values. Specifically, $M_{\mathrm{w}}$ and $M_{\mathrm{n}}$ molecular weights were 69100 and $43000 \mathrm{~g} / \mathrm{mol}$ for the commercial sample and 72,200 and $38800 \mathrm{~g} / \mathrm{mol}$ for the processed PLA with a force of $300 \mathrm{~N}$. The incorporation of the commercial and carefully dried HAp lead also to a scarce degradation, which could be mainly attributed to the increase of the applied force [34]. In this case, $M_{\mathrm{w}}$ and $M_{\mathrm{n}}$ 


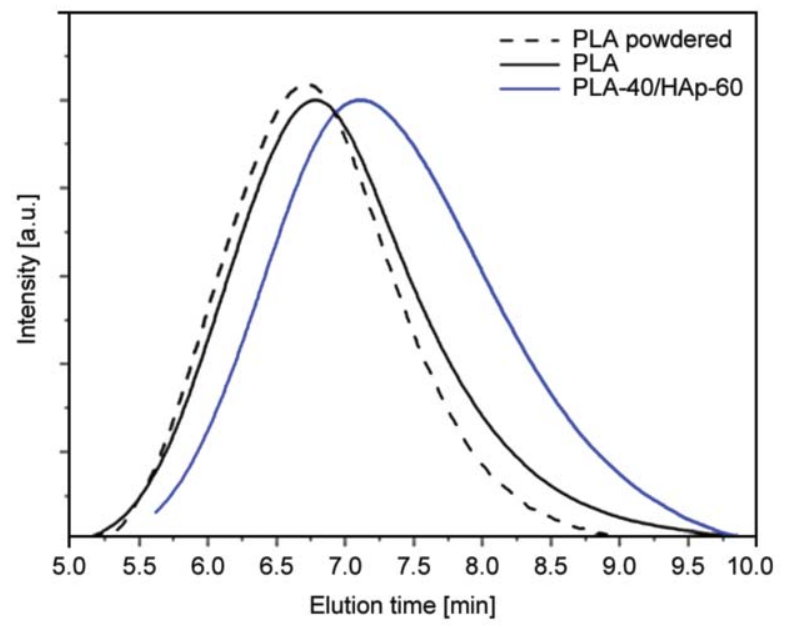

Figure 6. GPC chromatograms of commercial PLA powder, micromolded PLA and PLA-40/HAp-60. Processing parameters were $24 \mu \mathrm{m}, 1.2 \mathrm{~s}$ and $300 \mathrm{~N}$ (PLA) and $24 \mu \mathrm{m}, 1.2 \mathrm{~s}$ and $400 \mathrm{~N}$ (PLA/HAp).

values decreased to 69700 and $35900 \mathrm{~g} / \mathrm{mol}$. It should also be indicated that for PLA alone, $M_{\mathrm{n}}$ decreased to $37700 \mathrm{~g} / \mathrm{mol}$ when the processing force was increased to $400 \mathrm{~N}$. The incorporation of a ratio of HAp so high as $60 \mathrm{wt} \%$ had, therefore, a minimum influence on degradation.

The incorporation of HAp had a clear nucleation effect; thus, the cold crystallization exothermic peak of PLA/HAp composite shifted to a lower temperature (Figure 7). This behavior is not proportional to the HAp amount, at least in the high value range between 20 and $60 \mathrm{wt} \%$, where all PLA/HAp nanocomposites showed a cold crystallization peak $10^{\circ} \mathrm{C}$ lower than that observed for neat PLA (i.e., $103.8^{\circ} \mathrm{C}$ with respect to $113.8^{\circ} \mathrm{C}$ ). In addition, the melting enthalpy of the composite increased if the real amount of PLA is taken into account (i.e., $25.9 \mathrm{~J} / \mathrm{g}$ become

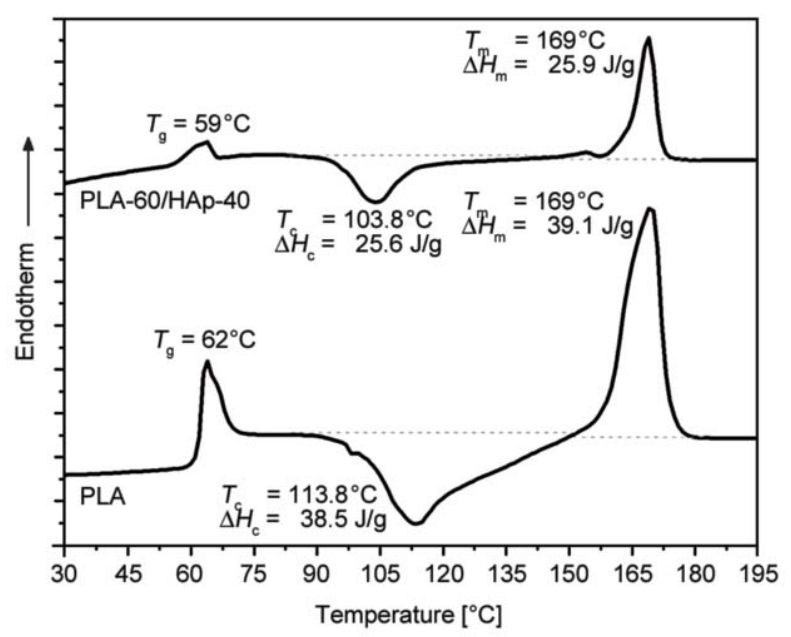

Figure 7. DSC heating runs of USM specimens of PLA and the representative PLA-60/HAp-40 composite.
$43.2 \mathrm{~J} / \mathrm{g}$ for a sample containing only $60 \mathrm{wt} \%$ of PLA, a higher value than the enthalpy of $39.1 \mathrm{~J} / \mathrm{g}$ determined for the neat PLA). Samples showed minimum differences between their $T_{\mathrm{g}}$ and the enthalpic relaxation peaks. It is interesting to note that after processing PLA and PLA/HAp-40 remained practically amorphous since cold crystallization and melting $\left(169^{\circ} \mathrm{C}\right)$ peaks had a similar enthalpy (i.e., $39 \mathrm{~J} / \mathrm{g}$ for neat PLA and $26 \mathrm{~J} / \mathrm{g}$ for PLA/HAp-40).

Dynamic WAXD profiles were also recorded during the heating run of USM specimens (Figures $8 \mathrm{a}$ and 8b). An amorphous profile was recorded for the PLA specimen at room temperature, but around $104^{\circ} \mathrm{C}$, the cold crystallization of PLA started as evidenced by the apparition of $\alpha$-form characteristic peaks [ 40 , 41] at scattering vector $\left(q=2 \pi / d\right.$, ${ }_{\mathrm{d}}$ being the Bragg spacing) values of $11.5,13.3$ and $15.5 \mathrm{~nm}^{-1}$ (i.e., Bragg spacings of $0.546,0.472$ and $0.405 \mathrm{~nm}$ that correspond to $(200)+(110),(203)$ and (015) reflections, respectively). These peaks started to reach the maximum intensity around $125^{\circ} \mathrm{C}$ (see Figure 8c). Then a partial melting of defective lamellae took place before a complete fusion that ended around $180^{\circ} \mathrm{C}$. The behavior of the composite was completely similar except by the presence of the crystalline HAp peak at $18.15 \mathrm{~nm}^{-1}$ (Bragg spacing of $0.34 \mathrm{~nm})[4,37]$. The main difference between PLA reflections of the processed specimens concern to the relative intensity of diffraction peaks and even to their broadness (Figure 8d), which suggests the development of smaller PLA crystals in the composite as presumably from its higher nucleation density. Incorporation of HAp improved mechanical properties of the composite in terms on the Young modulus, which logically increased due to the higher global crystallinity of the sample and the higher modulus of the HAp component. Thus, values of 847, 800, 780 and $754 \mathrm{MPa}$ were evaluated for specimens with HAp loads of $60,40,35$ and $20 \mathrm{wt} \%$, respectively, while a modulus of $707 \mathrm{MPa}$ was measured for USM PLA. On the contrary, the elongation at break slightly decreased as a consequence of the lower cohesion between PLA and HAp (i.e., from $11.4 \%$ for neat PLA to $11.0,10$ and $9.5 \%$ for composites with HAp content of 20,40 , and $60 \mathrm{wt} \%$, respectively). The combination of the two factors led to a practically constant maximum tensile strength (i.e., $58 \mathrm{MPa}$ for PLA and 62,60 , and $59 \mathrm{MPa}$ for composites with HAp contents of 60,40 , and $20 \mathrm{wt} \%$, respectively). For the sake of clarity, Figure 9 compares the stress-strain 

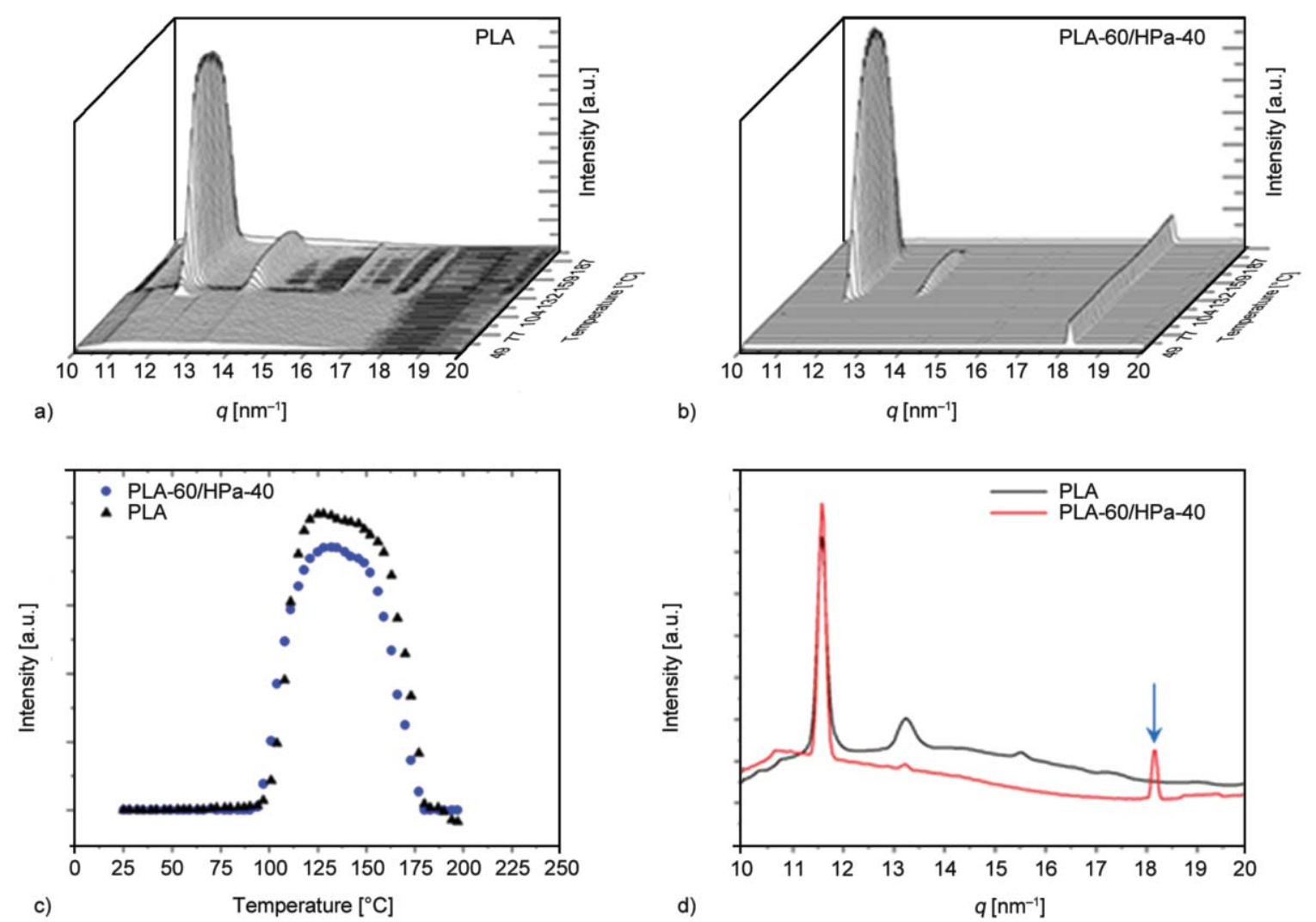

Figure 8. Three-dimensional representation of WAXD profiles of USM PLA (a) and PLA-60/HAp-40 (b) specimens. c) Intensity evolution of the main PLA peak during heating $\left(10^{\circ} \mathrm{C} / \mathrm{min}\right)$ from room temperature to fusion. $\left.\mathrm{d}\right)$ Comparison of WAXD profiles recorded at $125^{\circ} \mathrm{C}$ of PLA and PLA-60/HAp-40 specimens. Arrow points out the reflection corresponding to the crystalline HAp.

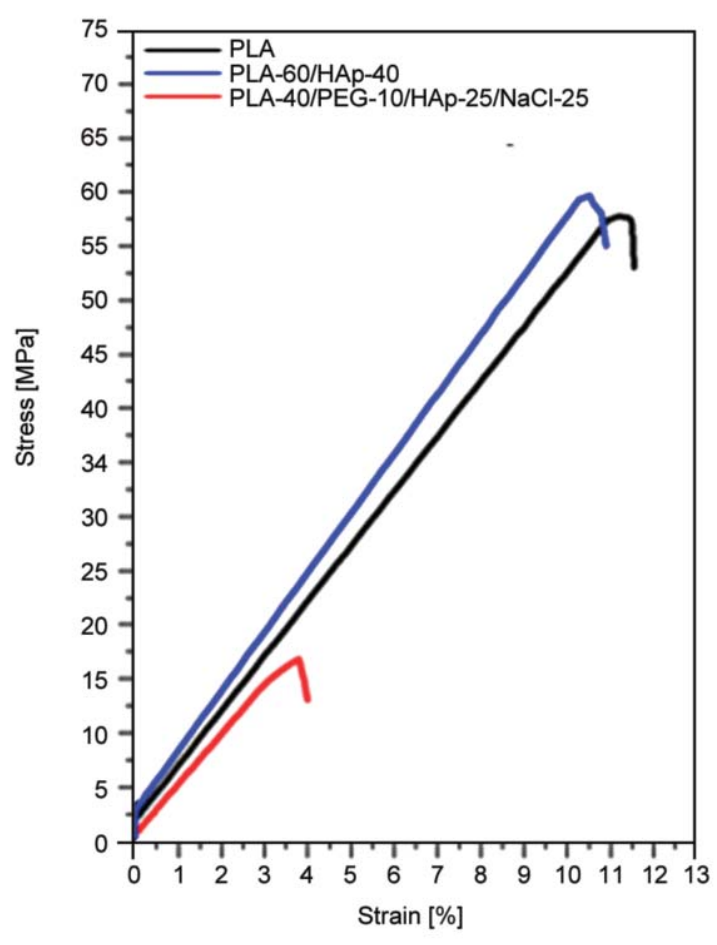

Figure 9. Stress-strain plots obtained from the representative indicated samples. PLA-40/PEG-10/HAp-25/NaCl25 (PLA/HAp scaffold) is also added for comparison purposes. profiles of micromolded PLA and PLA-60/HAp-40 specimens.

The incorporation of HAp slightly increased the hydrophilicity of the processed specimen., which is a positive effect to promote cell growth. Thus, the contact angle determined for the USM PLA specimen decreased to $63^{\circ}$ and $69^{\circ}$ for composites having HAp contents of 60 and $20 \mathrm{wt} \%$, respectively (Figure 10).

\subsection{Preparation of porous PLA/HAp scaffolds by ultrasound micromolding}

The salt leaching technique has been employed in order to get porous PLA/HAp specimens. To this end, $\mathrm{NaCl}$ and PEG have been incorporated in the initial mixture before processing. This procedure has recently been reported as a highly effective method to provide porosity in USM specimens [42]. Therefore, $\mathrm{NaCl}$ particles were sieved to get a homogeneous distribution with a small average size that facilitated the solubilization process, and that was appropriate for the subsequent cell colonization. A certain ratio of water-soluble PEG was necessary to increase the hydrophilicity of the specimen and make feasible 

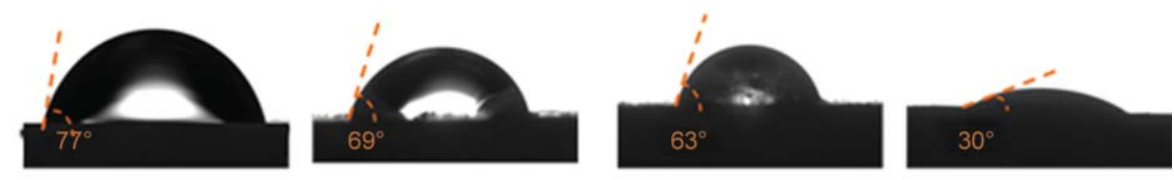

Figure 10. From left to right: water drop contact angle on PLA, PLA-80/HAp-20, PLA-40/HAp-60 and PLA-40/PEG10/HAp-25/NaCl-25 surfaces.

both the entrance of water inside the processed specimen and the salt removal. To get a significant porosity, USM was carried out using a mixture of PLA, PEG, $\mathrm{NaCl}$, and HAp powdered samples of 40,10 , 25 , and $25 \mathrm{wt} \%$, respectively. Note that the final scaffolds should have a HAp content close to a $40 \mathrm{wt} \%$ (i.e., $38 \mathrm{wt} \%$ ).

Processing parameters could be kept at the aboveselected values of $24 \mu \mathrm{m}, 400 \mathrm{~N}$ and $1.2 \mathrm{~s}$ since molds were completely filled, and specimens without coloration or other apparent degradation signals were obtained. In fact, GPC curves (not shown) of the processed specimens and after $\mathrm{NaCl}$ and PEG solubilization allowed estimating $M_{\mathrm{n}}$ and $M_{\mathrm{w}}$ values of 67100 and $39200 \mathrm{~g} / \mathrm{mol}$, respectively. SEM

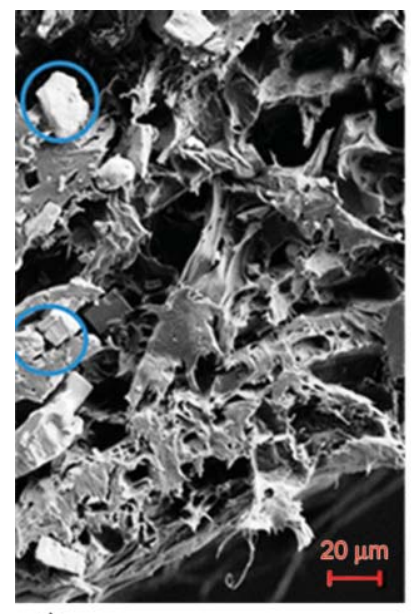

a)

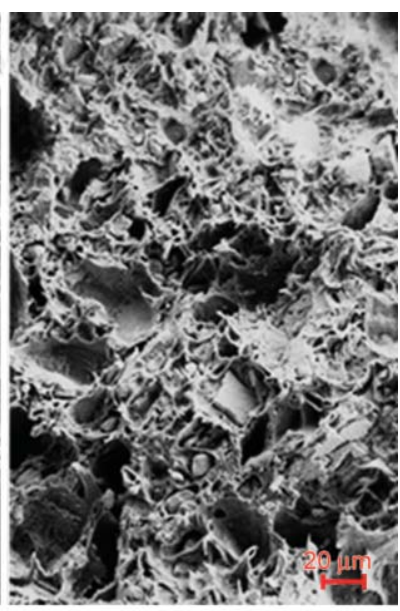

b)
Figure 11. SEM micrographs showing the inner cross sections of porous PLA/HAP scaffolds obtained by USM and subsequent washing (24 h) of PLA-50/ NaCl-25/HAp-25 (a) and PLA-40/PEG-10/NaCl25/HAp-25 (b) specimens. Blue circles pointed out the presence of some $\mathrm{NaCl}$ particles. micrographs (Figure 11) of specimen cross-sections revealed the high porosity of the final scaffold and the absence of white and geometrically regular salt particles, which by contrast, were still detectable when PEG was not incorporated (Figure 11). In this case, perfect porous interconnectivity was not attained, and therefore, some salt particles were not accessible to water.

\subsection{Characterization of PLA/HAp micromolded porous scaffolds}

Table 2 summarizes the results attained about weight percentages of total mass extraction (i.e., $\mathrm{NaCl}+$ $\mathrm{PEG}), \mathrm{NaCl}$ extraction, and porosity of representative scaffolds after the leaching process in water for $24 \mathrm{~h}$. For comparison purposes, values of PLA/NaCl40 and PLA/PEG-10/NaCl-40 specimens from previous works were also added [42]. These two samples revealed the essential role of PEG to enhance $\mathrm{NaCl}$ extraction. Note that the extraction of $\mathrm{NaCl}$ was only $40 \%$ when PEG was not present, whereas the addition of a small PEG percentage allowed getting a $\mathrm{NaCl}$ extraction close to $100 \%$. Moreover, as a consequence of this successful extraction, the porosity degree could be duplicated and attained a value close to $40 \%$.

Looking at the homologous samples loaded with HAp, a similar trend was observed: Incorporation of PEG increased the $\mathrm{NaCl}$ extraction yield as well as the porosity percentage.

Mechanical properties of the porous scaffold obviously decreased with respect to those determined for the solid PLA/HAp specimen having a similar composition (i.e., 38.4-40 wt $\%$ of HAp). Specifically,

Table 2. Mass and $\mathrm{NaCl}$ extraction percentages and degree of porosity of representative USM specimens.

\begin{tabular}{|l|c|c|c|}
\hline \multicolumn{1}{|c|}{ Sample $^{\text {a }}$} & $\begin{array}{c}\text { Mass extraction } \\
{[\%]}\end{array}$ & $\begin{array}{c}\text { NaCl extraction } \\
{[\%]}\end{array}$ & $\begin{array}{c}\text { Porosity } \\
{[\%]}\end{array}$ \\
\hline PLA-60/NaCl-40 & $40 \pm 8$ & $38 \pm 3$ & $20 \pm 5$ \\
\hline PLA-50/PEG-10/NaCl-40 & $98 \pm 6$ & $98 \pm 7$ & $39 \pm 3$ \\
\hline PLA-50/PEG-10/HAp-40 & - & $16 \pm 6$ \\
\hline PLA-50/NaCl-25/HAp-25 & $100 \pm 2$ & $41 \pm 3$ & $18 \pm 4$ \\
\hline PLA-40/PEG-10/NaCl-25/HAp-25 & $53 \pm 6$ & $92 \pm 11$ & $35 \pm 4$ \\
\hline
\end{tabular}

${ }^{a}$ The number after each component corresponds to the loaded $\mathrm{wt} \%$ in the feeding camera.

${ }^{\mathrm{b}}$ From reference [42]. 
Young modulus, elongation at break, and tensile strength decreased to $580 \mathrm{MPa}, 4 \%$, and $15.6 \mathrm{MPa}$, respectively (Figure 9).

Contact angle measurements showed a change from a value of $30^{\circ}$ determined for the processed specimen before the leaching process (Figure 10) to $60^{\circ}$ after extraction of PEG and $\mathrm{NaCl}$. Note that this angle is slightly lower than measured for the PLA/ HAp scaffold having $40 \mathrm{wt} \%$ of HAp (i.e., $70^{\circ}$ ). The difference suggests the presence of some residual $\mathrm{NaCl}$ since probably the increase of the specimen surface roughness and even the presence of voids should lead to a slight contact angle increase.

Figure 12 compares the TGA and DTGA curves of the USM PLA and PLA-40/PEG-10/NaCl-25/HAp25 specimens after PEG and salt extraction. HAp provided a slight thermal stabilization and increased the onset decomposition temperature (i.e., from 345 to $362^{\circ} \mathrm{C}$ ) as well the DTGA peak temperature (i.e., from 368 to $384^{\circ} \mathrm{C}$ ). The residue detected at $550^{\circ} \mathrm{C}$ was $29.2 \%$, a value in relatively good agreement with the loaded amount of HAp ( $25 \mathrm{wt} \%)$. Nevertheless, the extraction of $\mathrm{NaCl}$ was uncomplete, being the $\mathrm{NaCl}$ extraction percentage (84\%) slightly worse than that evaluated by conductivity measurements.

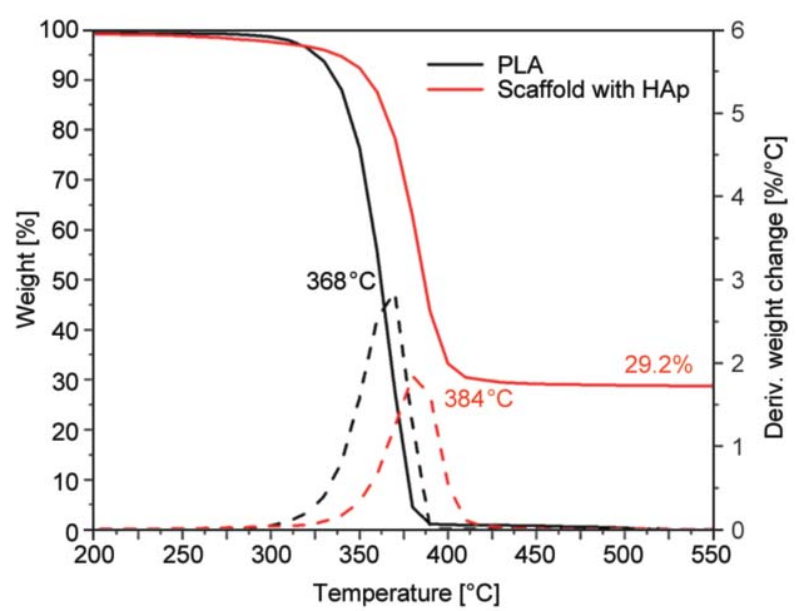

Figure 12. TGA (solid lines) and DTGA (dashed lines) profiles of neat PLA and the porous PLA/HAp scaffold prepared by USM.

The incorporation of HAp in materials used for different biomedical applications has an interest in order to improve biocompatibility and favor cell viability [1-3]. Particular attention merits the enhancement of the growth of bone tissue cells by biomineralization $[13,14]$. The advantages of HAp incorporation are additive to the porous character of the final scaffold.

Figure 13 compares the growth of MDCK cells onto specimens of neat PLA and representative scaffolds
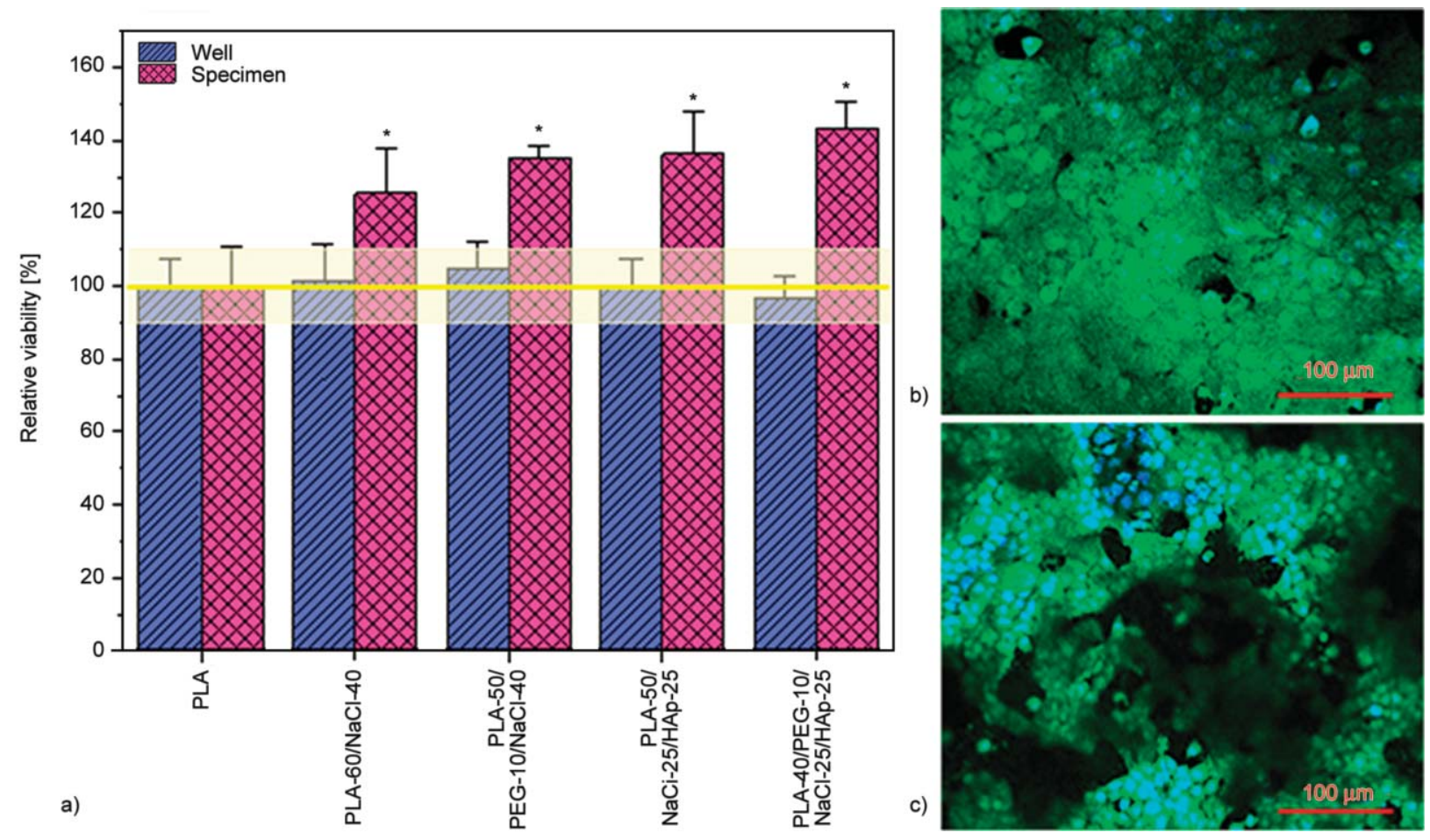

b)

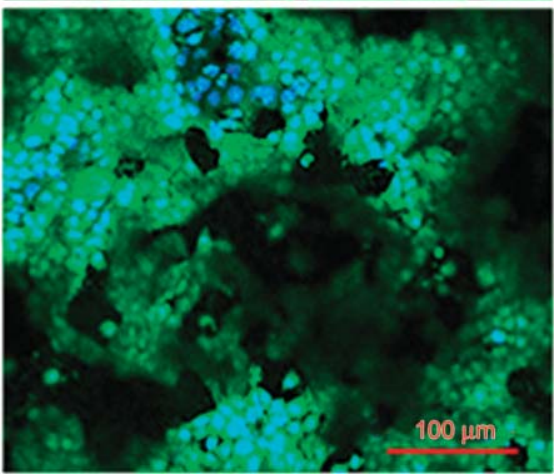

Figure 13. a) Bar graphic showing the relative cell proliferation determined at 7 days of culture for USM specimens of the indicated representative specimens. Asterisks indicate $p<0.05$ vs PLA scaffold (ANOVA-Tukey test). Yellow box indicates mean \pm SD for the control. Fluorescence micrographs showing the cell grown are also given in the right part for non-porous PLA (b) and porous PLA/HAp (i.e., from PLA-40/PEG-10/NaCl-25/HAp-25) (c). The cells were stained for nuclei (DAPI, blue) and actin (phalloidin, green). 
with and without HAp. Results pointed out the absence of cytotoxicity and the good biocompatibility of PLA since cell viability was like the control (yellow line). However, a significative higher relative cell viability $(p<0.05)$ was found for the porous samples as a consequence of their higher adhesion area. Despite the greatest improvement observed for porous specimens, it is also clear that the addition of HAp was beneficial, and a small increase in cell viability was detected. Therefore, cell proliferation increased by 45 and $30 \%$ with respect to the control for PLA scaffolds with and without HAp. Figure 13 also compares the relative viability on the specimen and onto the well once the specimen was removed. Results attained with the well were similar, as expected, to those found with the control.

Fluorescence micrographs showed the formation of a uniform cell monolayer onto the surface of the PLA specimen. However, cells in the porous scaffold can penetrate the porous surface and fill the voids of the sample, as evidenced by their growth in different planes.

\section{Conclusions}

Hybrid scaffolds of polylactide and hydroxyapatite can successfully be obtained through a new micromolding technology based on the application of ultrasound as the energy source. Specimens showed a minimum degradation and were obtained with a processing time so low as $1.2 \mathrm{~s}$ and a minimum material loss. Micropieces showed a relatively homogeneous distribution of HAp particles except for their surfaces. The maximum amount of HAp that could be loaded keeping a correct fluency in the feeding channels was $60 \mathrm{wt} \%$, a content that rendered materials with higher mechanical properties than non-loaded specimens (e.g., Young modulus of $847 \mathrm{MPa}$ in front of $707 \mathrm{MPa}$ ). PLA was practically amorphous after processing, although micro pieces could subsequently undergo cold crystallization. The quality of HAp was fundamental to get specimens without degradation and coloration as a consequence of cavitation phenomena induced by the decomposition of synthesis byproducts such as carbonate and nitrate salts. Porous scaffolds of PLA/HAp could also be prepared by adding water-soluble compounds (e.g., polyethylene glycol and $\mathrm{NaCl}$ salts) in the feeding mixture and performing a subsequent leaching process. The HAp content should be reduced to $38 \mathrm{wt} \%$ to get materials with a porosity of $35 \%$. Young modulus and tensile strength logically decreased with respect to the non-porous PLA samples, but acceptable values of 580 and $15.6 \mathrm{MPa}$ were attained. The presence of HAp provided thermal stability and allowed to increase the hydrophilicity, an interesting feature for biological applications. In the same way, it was found that both porosity and presence of HAp particles favored cell colonization and specifically, an increase of the proliferation of assayed MDCK cells around $40 \%$ with respect to the control was found.

\section{Acknowledgements}

The authors acknowledge support from MINECO and FEDER (RTI2018-101827-B-I00) and the Generalitat de Catalunya (2017SGR373). Diffraction experiments were performed at the NCD-SWEET beamline at ALBA Synchrotron with the collaboration of ALBA staff.

\section{References}

[1] Bonassar L. J., Vacanti C. A.: Tissue engineering: The first decade and beyond. Journal of Cellular Biochemistry, 72, 297-303 (1998).

https://doi.org/10.1002/(sici)10974644(1998)72:30/31+<297::aid-jcb36>3.0.co;2-6

[2] Atala A.: Tissue engineering and regenerative medicine: Concepts for clinical application. Rejuvenation Research, 7, 15-31 (2004).

https://doi.org/10.1089/154916804323105053

[3] Martin I., Wendt D., Heberer M.: The role of bioreactors in tissue engineering. Trends in Biotechnology, 22, 80-86 (2004).

https://doi.org/10.1016/j.tibtech.2003.12.001

[4] Choi D., Marra K. G., Kumta P. N.: Chemical synthesis of hydroxyapatite/poly( $\varepsilon$-caprolactone) composites. Materials Research Bulletin, 39, 417-432 (2004). https://doi.org/10.1016/j.materresbull.2003.10.013

[5] Zhang Y., Lu J.: A simple method to tailor spherical nanocrystal hydroxyapatite at low temperature. Journal of Nanoparticle Research, 9, 589-594 (2007). https://doi.org/10.1007/s11051-006-9177-3

[6] Ioku K., Yamauchi S., Fujimori H., Goto S., Yoshimura M.: Hydrothermal preparation of fibrous apatite and apatite sheet. Solid State Ionics, 151, 147-150 (2002). https://doi.org/10.1016/S0167-2738(02)00593-3

[7] Li X., Feng Q., Liu X., Dong W., Cui F.: Collagenbased implants reinforced by chitin fibres in a goat shank bone defect model. Biomaterials, 27, 1917-1923 (2006). https://doi.org/10.1016/j.biomaterials.2005.11.013

[8] Wei J., Li Y.: Tissue engineering scaffold material of nano-apatite crystals and polyamide composite. European Polymer Journal, 40, 509-515 (2004). https://doi.org/10.1016/j.eurpolymj.2003.10.028 
[9] Ignjatovic N., Suljovrujic E., Budinski-Simendic J., Krakovsky I., Uskokovic D.: Evaluation of hot-pressed hydroxyapatite/poly-L-lactide composite biomaterial characteristics. Journal of Biomedical Materials Research B Applied Biomaterials, 71, 284-294 (2004). https://doi.org/10.1002/jbm.b.30093

[10] Lopes M. S., Jardini A. L., Filho R. M.: Poly (lactic acid) production for tissue engineering applications. Procedia Engineering, 42, 1402-1413 (2012). https://doi.org/10.1016/j.proeng.2012.07.534

[11] Auras R., Lim L-T., Selke S. E. M., Tsuji H.: Poly(lactic acid): Synthesis, structures, properties, processing, and applications. Wiley, Hoboken (2010).

https://doi.wiley.com/10.1002/9780470649848

[12] Armentano I., Bitinis N., Fortunati E., Mattioli S., Rescignano N., Verdejo R., Lopez-Manchado M. A., Kenny J. M.: Multifunctional nanostructured PLA materials for packaging and tissue engineering. Progress in Polymer Science, 38, 1720-1747 (2013). https://doi.org/10.1016/j.progpolymsci.2013.05.010

[13] Yun Y-P., Kim S-J., Lim Y-M., Park K., Kim H-J., Jeong S-I., Kim S. E., Song H-R.: The effect of alendronate-loaded polycarprolactone nanofibrous scaffolds on osteogenic differentiation of adipose-derived stem cells in bone tissue regeneration. Journal of Biomedical Nanotechnology, 10, 1080-1090 (2014). https://doi.org/10.1166/jbn.2014.1819

[14] Zhou H., Lawrence J. G., Bhaduri S. B.: Fabrication aspects of PLA-CaP/PLGA-CaP composites for orthopedic applications: A review. Acta Biomaterialia, 8, 19992016 (2012).

https://doi.org/10.1016/j.actbio.2012.01.031

[15] Wei G., Ma P. X.: Structure and properties of nano-hydroxyapatite/polymer composite scaffolds for bone tissue engineering. Biomaterials, 25, 4749-4757 (2004). https://doi.org/10.1016/j.biomaterials.2003.12.005

[16] Zhang R., Ma P. X.: Poly( $\alpha$-hydroxyl acids)/hydroxyapatite porous composites for bone-tissue engineering. I. Preparation and morphology. Journal of Biomedical Materials Research, 44, 446-455 (1999).

https://doi.org/10.1002/(sici)10974636(19990315)44:4<446::aid-jbm11>3.0.co;2-f

[17] Cool S. M., Kenny B., Wu A., Nurcombe V., Trau M., Cassady A. I., Grøndahl L.: Poly(3-hydroxybutyrateco-3-hydroxyvalerate) composite biomaterials for bone tissue regeneration: In vitro performance assessed by osteoblast proliferation, osteoclast adhesion and resorption, and macrophage proinflammatory response. Journal of Biomedical Materials Research Part A, 82, 599610 (2007).

https://doi.org/10.1002/jbm.a.31174

[18] Ren J., Zhao P., Ren T., Gu S., Pan K.: Poly (D,L-lactide)/nano-hydroxyapatite composite scaffolds for bone tissue engineering and biocompatibility evaluation. Journal of Materials Science: Materials in Medicine, 19, 1075-1082 (2008).

https://doi.org/10.1007/s10856-007-3181-8
[19] Diao H., Si Y., Zhu A., Ji L., Shi H.: Surface modified nano-hydroxyapatite/poly(lactide acid) composite and its osteocyte compatibility. Materials Science and Engineering: C, 32, 1796-1801 (2012). https://doi.org/10.1016/j.msec.2012.04.065

[20] Zhang C. Y., Zhang C. L., Wang J. F., Lu C. H., Zhuang Z., Wang X. P., Fang Q. F.: Fabrication and in vitro investigation of nanohydroxyapatite, chitosan, poly(Llactic acid) ternary biocomposite. Journal of Applied Polymer Science, 127, 2152-2159 (2013). https://doi.org/10.1002/app.37795

[21] Han W., Zhao J., Tu M., Zeng R., Zha Z., Zhou C.: Preparation and characterization of nanohydroxyapatite strengthening nanofibrous poly(L-lactide) scaffold for bone tissue engineering. Journal of Applied Polymer Science, 128, 1332-1338 (2013).

https://doi.org/10.1002/app.38177

[22] Cheng C-C., Banakar H., Ooi B-T., Jen C-K.: Melting quality of polymers in internal mixer diagnosed by ultrasound. International Polymer Processing, 24, 375383 (2009).

https://doi.org/10.3139/217.2166

[23] Sacristán M., Plantá X., Morell M., Puiggalí J.: Effects of ultrasonic vibration on the micro-molding processing of polylactide. Ultrasonics Sonochemistry, 21, 376-386 (2014). https://doi.org/10.1016/j.ultsonch.2013.07.007

[24] Planellas M., Sacristán M., Rey L., Olmo C., Aymamí J., Casas M. T., del Valle L. J., Franco L., Puiggalí J.: Micro-molding with ultrasonic vibration energy: New method to disperse nanoclays in polymer matrices. Ultrasonics Sonochemistry, 21, 1557-1569 (2014). http://doi.org/10.1016/j.ultsonch.2013.12.027

[25] Kellomäki M., Törmälä P.: Ultrasonic moulding of bioabsorbable polymers and polymer/drug composites. Journal of Material Science Letters, 16, 1786-1789 (1997). https://doi.org/10.1023/A:1018548130539

[26] Sato A., Ito H., Koyama K.: Study of application of ultrasonic wave to injection molding. Polymer Engineering and Science, 49, 768-773 (2009).

https://doi.org/10.1002/pen.21268

[27] Li J. B., Xu K. K., Lin X. B., Wu X. Y., Gao G. L.: Research on the flow characteristics of polymer injection molding under ultrasonic vibration and plastics' mechanical strength. Applied Mechanics and Materials, 37-38, 1092-1100 (2010).

https://doi.org/10.4028/www.scientific.net/AMM.37-38.1092

[28] Giboz J., Copponnex T., Mélé P.: Microinjection molding of thermoplastic polymers: A review. Journal of Micromechanics and Microengineering, 17, R96-R109 (2007).

https://doi.org/10.1088/0960-1317/17/6/R02

[29] Chen J., Chen Y., Li H., Lai S-Y., Jow J.: Physical and chemical effects of ultrasound vibration on polymer melt in extrusion. Ultrasonics Sonochemistry, 17, 66$71(2010)$.

https://doi.org/10.1016/j.ultsonch.2009.05.005 
[30] Chen G., Guo S., Li H.: Ultrasonic improvement of rheological behavior of polystyrene. Journal of Applied Polymer Science, 84, 2451-2460 (2002).

https://doi.org/10.1002/app.10535

[31] Heredia-Rivera U., Ferrer I., Vázquez E.: Ultrasonic molding technology: Recent advances and potential applications in the medical industry. Polymers, 11, 667/1667/25 (2009).

https://doi.org/10.3390/polym11040667

[32] Díaz A., Franco L., Casas M. T., del Valle L. J., Aymamí J., Olmo C., Puiggalí J.: Preparation of micro-molded exfoliated clay nanocomposites by means of ultrasonic technology. Journal of Polymer Research, 21, 584/1584/12 (2014).

https://doi.org/10.1007/s10965-014-0584-3

[33] Olmo C., Amestoy H., Casas M. T., Martínez J. C., Franco L., Sarasua J. R., Puiggalí J.: Preparation of nanocomposites of poly( $\varepsilon$-caprolactone) and multi-walled carbon nanotubes by ultrasound micro-molding. influence of nanotubes on melting and crystallization. Polymers, 9, 322/1-322/18 (2017).

https://doi.org/10.3390/polym9080322

[34] Olmo C., Franco L., del Valle L. J., Puiggalí J.: Preparation of medicated polylactide micropieces by means of ultrasonic technology. Applied Sciences, 9, 2360/12360/17 (2019).

https://doi.org/10.3390/app9112360

[35] Berzina-Cimdina L., Borodajenko N.: Research of calcium phosphates using Fourier transform infrared spectroscopy. in 'Materials science, engineering and technology' (ed.: Theophile P. T.) InTech, Rijeka, 123-148 (2011).

https://doi.org/10.5772/36942
[36] Mosmann T.: Rapid colorimetric assay for cellular growth and survival: Application to proliferation and cytotoxicity assays. Journal of Immunological Methods, 65, 55-63 (1983).

https://doi.org/10.1016/0022-1759(83)90303-4

[37] Herdocia-Lluberes C. S., Laboy-López S., Morales S., Gonzalez-Robles T. J., González-Feliciano J. A., Nicolau E.: Evaluation of synthesized nanohydroxyapatite-nanocellulose composites as biocompatible scaffolds for applications in bone tissue engineering. Journal of Nanomaterials, 2015, 310935/1--310935/9 (2015).

https://doi.org/10.1155/2015/310935

[38] Rehman I., Bonfield W.: Characterization of hydroxyapatite and carbonated apatite by photo acoustic FTIR spectroscopy. Journal of Materials Science: Materials in Medicine, 8, 1-4 (1997). https://oi.org/10.1023/A:1018570213546

[39] Landi E., Celotti G., Logroscino G., Tampieri A.: Carbonated hydroxyapatite as bone substitute. Journal of the European Ceramic Society, 23, 2931-2937 (2003). https://doi.org/10.1016/S0955-2219(03)00304-2

[40] de Santis P., Kovacs A. J.: Molecular conformation of poly(S-lactic acid). Biopolymers, 6, 299-306 (1968). https://doi.org/10.1002/bip.1968.360060305

[41] Hoogsteen W., Postema A. R., Pennings A. J., ten Brinke G., Zugenmaier P.: Crystal structure, conformation and morphology of solution-spun poly(L-lactide) fibers. Macromolecules, 23, 634-642 (1990). https://doi.org/10.1021/ma00204a041

[42] Olmo C., Franco L., del Valle L. J., Puiggalí J.: Biodegradable polylactide scaffolds with pharmacological activity by means of ultrasound micromolding technology. Applied Sciences, 10, 3106/1-3106/22 (2020). https://doi.org/10.3390/app10093106 